\title{
Programmed Cell Death 1-Directed Immunotherapy for Enhancing T-Cell Function
}

\author{
Koichi Araki, Ben Youngblood, ANd Rafi Ahmed \\ Emory Vaccine Center and Department of Microbiology and Immunology, \\ Emory University School of Medicine, Atlanta, Georgia 30322 \\ Correspondence: rahmed@emory.edu
}

\begin{abstract}
T-cell exhaustion is a unique state that appears during many chronic infections and cancer and is characterized by loss of proliferative capacity and effector function. Complex mechanisms are involved in this T-cell dysfunction but an inhibitory receptor, PD-1, has been identified as a major regulator of T-cell exhaustion. Blockade of the PD-1 pathway can reinvigorate exhausted $\mathrm{T}$ cells, resulting in better control of chronic infections and cancer. Notably, recent clinical studies have revealed that PD-1-directed immunotherapy is highly effective in cancer patients, demonstrating that PD-1 is a promising therapeutic target in humans. In this review, we summarize our current understanding of the epigenetic regulation of PD-1 expression in T cells and discuss potential combination therapy with PD-1 blockade toward developing more effective treatment for chronic infections and cancer.
\end{abstract}

CD8 T cells play an essential role in controlling intracellular infections and tumors (Kaech and Wherry 2007). However, once the CD8 T cells fail to eliminate the infections and tumors, chronic antigen stimulation leads them to exhaustion characterized by impaired cytokine production, loss of proliferative capacity, and reduced killing activity (Zajac et al. 1998). Although complex mechanisms are involved in T-cell exhaustion, accumulating evidence indicates that programmed cell death 1 (PD-1; CD279) is a major player in the process of exhaustion. PD-1 is an inhibitory receptor that is expressed not only on exhausted $\mathrm{T}$ cells but also on a variety of hematopoietic cells including B cells and functional T cells in response to activation (Keir et al. 2008; Rudd et al. 2009; Francisco et al. 2010). PD-1 mediates inhibitory signals via binding to two distinct ligands, PD-L1 (B7-H1/ CD274) and PD-L2 (B7-DC/CD273) (Fig. 1). PD-L1 is constitutively expressed on both hematopoietic and nonhematopoietic cells and is induced by cytokine stimulation, whereas PD-L2 expression is limited to certain types of cells such as activated macrophages, dendritic cells (DCs), and a subset of B cells (Keir et al. 2008; Rudd et al. 2009; Francisco et al. 2010). PD-1 ligation with its ligands inhibits T-cell receptor (TCR) signals as well as phosphatidylinositol-3-kinase (PI3 K) activity by recruiting phosphatase SHP1 and SHP2 to the cytoplasmic domain (Fig. 1). PD-1 is up-regulated on exhausted CD8 T cells in patients with chronic infection or cancer and the PD-1 signals inhibit proliferation and effector function of the T cells. Blockade of PD-1/PD-L1 interaction can reinvigorate function of the exhausted CD8 $\mathrm{T}$ cells, indicating that PD-1 blockade therapy is a promising strategy against chronic infection and cancer. Recent studies have uncovered novel mechanisms for epigenetic control of PD-1 expression and have shown broader implication for CD8 T-cell differentiation. In this review, we summarize current understanding on the epigenetic regulation of PD-1 expression in CD8 T cells and discuss potential combination therapy with PD-1 blockade.

\section{EPIGENETIC REGULATION OF PD-1 GENE EXPRESSION}

It is quite clear that the up-regulated expression and subsequent signaling by PD-1 plays a dominant role in suppressing the effector response from CD8 T cells during chronic viral infection. Therefore, in addition to understanding the molecular events that transpire following ligation of the PD-1 receptor with its ligand, significant effort has been focused on understanding the mechanisms for transcriptional up-regulation of PD-1 expression and the impact on these transcriptional regulatory mechanism during transient versus persistent stimulation to the CD8 T cell during acute versus chronic viral infection, respectively.

During acute viral infection, antigen-specific CD8 $\mathrm{T}$ cells transiently up-regulate the transcriptional expression of PD-1, and upon viral control rapidly down-regulate PD-1 transcription (Fig. 2A). Similarly, PD-1 expression is up-regulated on antigen-specific CD8 $\mathrm{T}$ cells during chronic viral infection, but it remains up-regulated during viral persistence (Fig. 3A) (Barber et al. 2006; Wherry et al. 2007). Not surprisingly, when the exhausted CD8 $\mathrm{T}$ cells are then removed from the source of antigen, by either antiviral therapy (HAART with HIV-infected patients) (Day et al. 2006; Trautmann et al. 2006) or in experimental systems where antigen-specific CD8 T cells can be adoptively transferred into antigen-free animals, PD-1 expression is significantly reduced (Fig. 3A) (Blatt- 


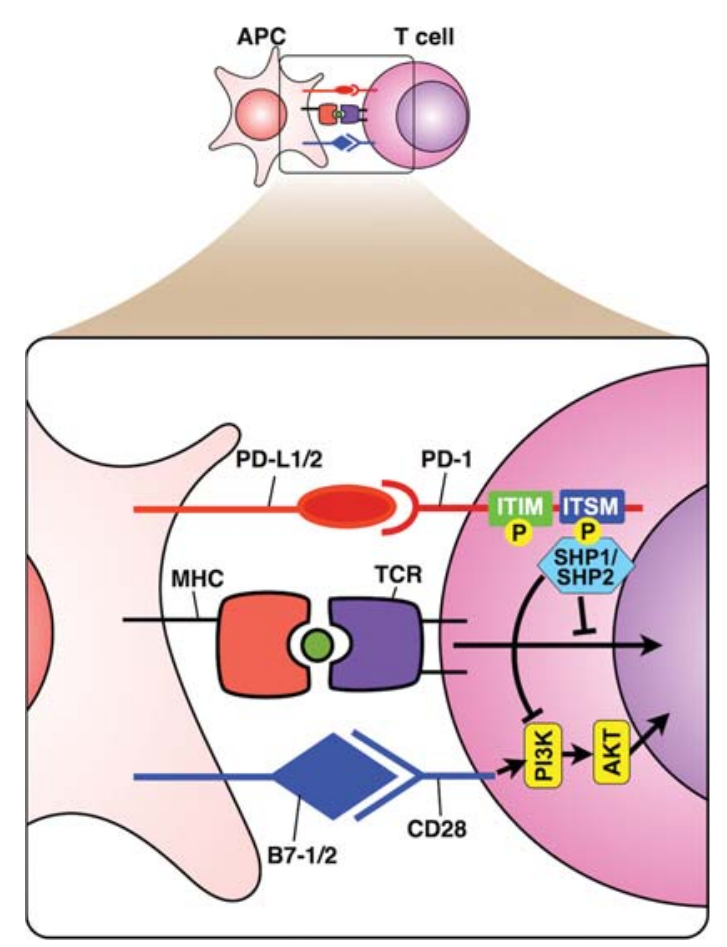

Figure 1. PD-1 signaling. PD-1 has two motifs in the cytoplasmic tail: an immunoreceptor tyrosine-based inhibition motif (ITIM) and an immunoreceptor tyrosine-based switch motif (ITSM). The ITSM is important for PD-1-mediated inhibitory function. The phosphatases SHP1 and SHP2 can bind to the ITSM and then inhibit TCR signaling as well as PI3K activated by CD28.

man et al. 2009; Angelosanto et al. 2012). These data indicate that, indeed, TCRs drive PD-1 expression at the protein and transcript levels. To better understand the impact of sustained TCR signaling on PD-1 transcription, early investigation of transcriptional regulatory mechanisms of functional memory versus exhausted CD8 $\mathrm{T}$ cells focused on the noncoding upstream regions of the PD-1 transcriptional start site that were conserved among mammals. Attention to these regions was based on the idea that evolutionary conservation of transcriptional regulatory regions occurs as result of selective pressure shared among species that preserves mechanisms fundamental to the biological function of the cell. These regions were subsequently described as Conserved Region $\mathrm{C}$ and $\mathrm{B}$ (CR-C and CR-B) and indeed contain critical transcriptional regulatory features (Oestreich et al. 2008).

Within the conserved regulatory regions reside potential binding sites for transcription factors previously described to play important roles in CD8 T-cell effector responses. A direct role in regulating PD-1 expression by several of these transcription factors, including NFATc1, AP-1, and T-bet, have now been reported (Oestreich et al. 2008; Kao et al. 2011; Xiao et al. 2012). Surprisingly, many of these transcription factors are expressed in both functional and exhausted CD8 T cells, albeit at different levels, suggesting that transcriptional regulation of PD-1 by these factors is further con- trolled by additional mechanisms. A clue regarding the mechanisms involved in this additional layer of transcriptional control of PD-1 expression came from studies that examined PD-1 reexpression kinetics of functional memory and exhausted CD8 T cells. Several laboratories observed that in vivo and in vitro stimulation of functional memory CD8 T cells and PD- $1^{\text {lo }}$ exhausted CD8 T cells resulted in both cell populations reexpressing $\mathrm{PD}-1$, but surprisingly the exhausted CD8 T cells reexpressed PD-1 much faster than the functional memory CD8 T cells (Fig. 3C) (Youngblood et al. 2011). These data indicated that the PD-1 transcriptional regulatory region in exhausted $\mathrm{T}$ cells is "poised" for activation.

Transcriptional poising is known to be coupled to chromatin accessibility and can be heritably maintained by acquired epigenetic modifications. Using mouse and human model systems, we analyzed the epigenetic programming at PD-1 CR-C and CR-B in CD8 T cells during acute and chronic infections (Youngblood et al. 2011). Indeed, up-regulation of PD-1 during both acute and

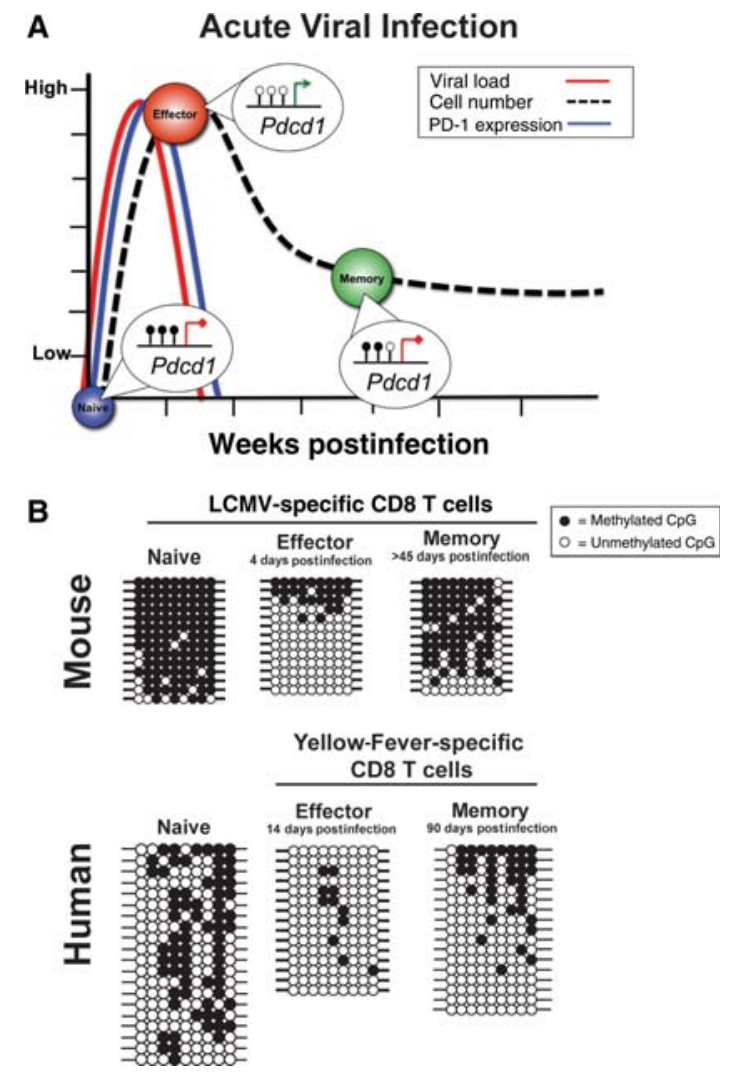

Figure 2. Transient DNA PD-1 promoter demethylation in antigen-specific CD8 T cells during acute viral infection. (A) Summary of viral load (red line), antigen-specific CD8 T-cell expansion and maintenance (dashed black line), PD-1 expression (blue line), and promoter methylation status (open/closed lollipops) during a primary acute viral infection. $(B)$ Bisulfite sequencing methylation analysis of PD-1 regulatory regions from fluorescence-activated cell sorting (FACS) purified virus-specific CD8 T cells during acute viral infection: (top ) mouse lymphocytic choriomeningitus virus (LCMV)-specific naïve, day 4 effector, and memory CD8 T cells. (Bottom) Human naïve, yellow-feverspecific day 14 effector, and day 90 memory CD8 T cells. 
A

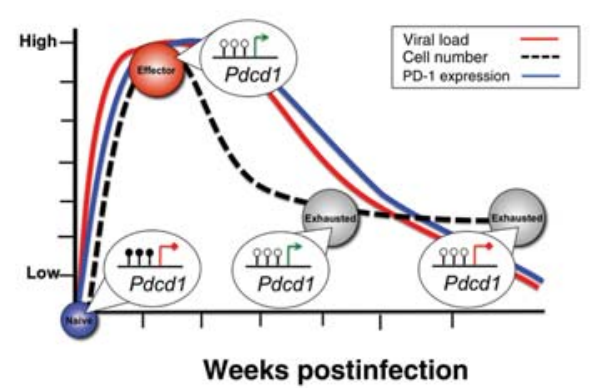

B

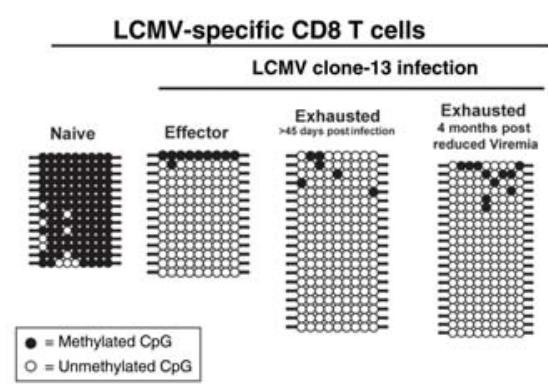

C

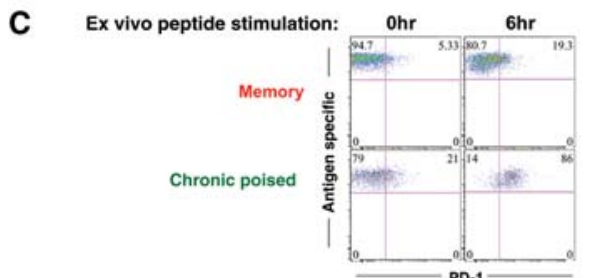

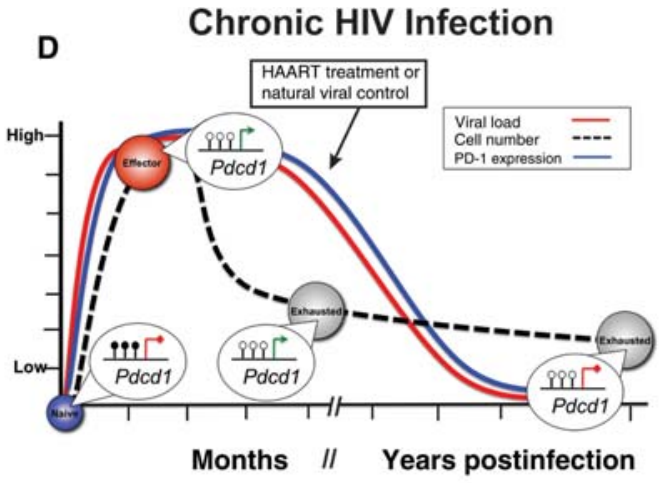

E

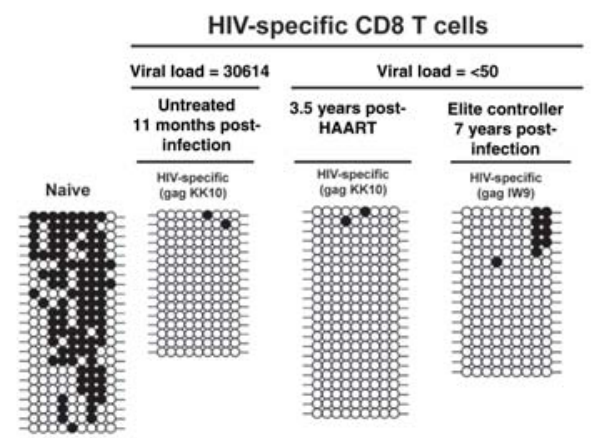

Figure 3. DNA remethylation of the PD-1 transcription regulatory region is impaired during mouse and human chronic viral infection. (A) Summary of viral load (red line), antigen-specific CD8 T-cell expansion and maintenance (dashed black line), PD-1 expression (blue line), and promoter methylation status (open/closed lollipops) during a chronic murine LCMV infection. (B) Bisulfite sequencing methylation analysis of PD-1 regulatory regions from FACS purified LCMV-specific CD8 T cells during chronic viral infection; mouse LCMV-specific naïve, day 8 effector, exhausted, and exhausted CD8 T cells from mice 4 mo following viral control to undetectable levels in the serum. (C) FACS analysis of PD-1 reexpression on infection matched fully functional memory and PD- $1^{10}$ exhausted mouse CD8 T cells. Gp33-specific CD8 T cells from acutely infected mice and chronically infected mice (several months after viral reduction) were in vitro stimulated with the cognate peptide for $6 \mathrm{~h}$. These data reveal that the unmethylated PD- ${ }^{\text {lo }}$ exhausted CD8 T cells are poised to reexpress PD-1 faster than methylated functional memory CD8 T cells. $(D)$ Summary of viral load (red line), antigen-specific CD8 T-cell expansion and maintenance (dashed black line), PD-1 expression (blue line), and promoter methylation status (open/closed lollipops) during chronic HIV infection. Reduction in viral load in infected individuals occurs from either HAART treatment or by natural mechanisms. $(E)$ Bisulfite sequencing methylation analysis of PD-1 regulatory region from FACS purified naïve and HIV-specific CD8 T cells from donors previral and postviral control.

chronic viral infection was coupled to demethylation of CpG sites residing in CR-C and CR-B in virus-specific CD8 T cells (Youngblood et al. 2011). Furthermore, we observed that during the effector-to-memory stage of the immune response to an acute viral infection, PD-1 regulatory regions became remethylated (Fig. 2B). Not surprisingly, the PD-1 regulatory regions remained demethylated in mouse exhausted CD8 T cells in the presence of high viral load (Fig. 3B). Interestingly, PD-1 regulatory regions remained unmethylated even after viral loads were significantly reduced (Fig. 3B) (Youngblood et al. 2011).

Building on our observations with the mouse LCMV model system, we next examined the DNA methylation program of PD-1 regulatory regions in HIV-specific CD8 $\mathrm{T}$ cells from progressors, elite controllers, and patients on antiretroviral therapy (HAART). Upon infection, HIV viral loads rapidly elevate and are sustained at high levels for several months. Following the peak expansion of HIV, viral loads remain elevated unless the infected individual undergoes HAART. In some cases, individuals known as elite controllers can control viral loads to levels undetectable by standard techniques, and viral loads can remain reduced for decades (Fig. 3D). Similar to mouse exhausted CD8 T cells, HIV-specific CD8 T cells in individuals with a high viral load had an unmethylated regulatory region. Furthermore, naïve cells from the infected individuals retained a methylated PD-1 regulatory region, indi- 
cating that demethylation is mediated by TCR ligation (Fig. 3E). Importantly, HIV-specific CD8 T cells were unable to recover the repressive epigenetic program at the PD-1 promoter after significant viral reduction in individuals who had undergone HAART for several years. Even more striking, PD- ${ }^{\text {lo }}$ HIV-specific CD8 T cells from elite controllers who had reduced viral loads for more than 10 years retained a demethylated PD-1 regulatory region (Fig. 3E). These data indicate that even if an established chronic infection can be controlled, the antigen-specific CD8 T cells retain a PD-1 locus poised for expression and subsequently premature termination of an effector response (Fig. 3B,E) (Youngblood et al. 2013). Thus, the implications of retaining an epigenetically accessible transcriptional regulatory region is that future therapies designed to fully resolve chronic infections will likely have to incorporate strategies that block PD-1 signaling or alter the epigenetic program of virus-specific CD8 $\mathrm{T}$ cells to retain down-regulation of PD-1 to target infected cells for lysis. The above data broadly highlight the significance of epigenetic modifications in facilitating transcriptional program of the differentiated state of functional memory and exhausted CD8 T cells. In addition to providing new insight into the current challenge of activating antigen-specific CD8 T cells to clear the HIV reservoir in chronically infected individuals, studies of PD-1 transcriptional regulation have furthered our understanding of how chronic viral infections evade the immune system by promoting tolerization programs within the antigen-specific T cells.

\section{PD-1-DIRECTED IMMUNOTHERAPY}

PD-1 plays an essential role in T-cell exhaustion during chronic viral infection. This was originally found in mice infected with chronic LCMV strain (Barber et al. 2006). In this study, we showed that exhausted CD8 T cells up-regulate PD-1 during chronic LCMV infection, and blockade of PD-1/PD-L1 interaction can reinvigorate function of the exhausted CD8 T cells and reduce viral load (Barber et al. 2006). In addition to this mouse study, the PD-1 expression on antigen-specific CD8 T cells was also found in HIV-infected people who were naïve to antiHIV treatment, and the expression levels were correlated with their functional impairment (Day et al. 2006; Petrovas et al. 2006; Trautmann et al. 2006). Blockade of the pathway in vitro improved function of these CD8 T cells. Similar results were observed in hepatitis $\mathrm{C}$ virus-infected people (Urbani et al. 2006; Radziewicz et al. 2007). These findings suggest that immunotherapy directed at PD-1 pathway is an attractive strategy to control chronic infections. Indeed, blockade of PD-1 using anti-PD-1 antibody in simian immunodeficiency virus (SIV)-infected macaques expanded virus-specific CD8 T-cell responses and improved their function (Velu et al. 2009). This enhanced T-cell immunity was accompanied by reduced viral load and prolonged survival of the SIV-infected macaques (Velu et al. 2009). Another study also reported that immunotherapy using anti-PD-1 antibody resulted in reduced viral load in hepatitis C virus-infected chimpan- zees (Fuller et al. 2013). Importantly, this study suggested that certain levels of preexisting hepatitis $\mathrm{C}$ virusspecific $\mathrm{T}$ cells were required for viral reduction associated with improved T-cell responses after anti-PD-1 antibody treatment (Fuller et al. 2013), supporting that this immunotherapy acts on virus-specific exhausted $T$ cells to rejuvenate their function. Thus, blockade of PD-1 pathway is a promising treatment to control chronic infections.

In addition, recent clinical trials showed that PD-1 blockade therapy was highly effective in patients with advanced cancer (melanoma, non-small-cell lung cancer, and ovarian cancer) (Brahmer et al. 2012; Topalian et al. 2012). Efficacy of the therapy against tumors in these studies was much higher than that of other immunotherapy regimens (Brahmer et al. 2012; Ribas 2012; Topalian et al. 2012).

\section{Potential Mechanisms of PD-1-Directed Immunotherapy}

Although exact cellular mechanisms of how PD-1 blockade restores the function of CD8 T-cell exhaustion are yet to be fully understood, there appears to be a potential model proposed from our experiments in which lethally irradiated PD-L1 $1^{-/-}$or wild-type (WT) mice were reconstituted with $\mathrm{PD}-\mathrm{L}^{-/}$or WT bone marrow and infected with LCMV (Mueller et al. 2010). Our study proposes a model that PD-1/PD-L1 interaction between antigen-presenting cells (APCs) and antigen-specific CD8 $\mathrm{T}$ cells negatively regulates proliferation of CD8 T cells as well as effector T-cell differentiation, whereas the interaction between infected nonhematopoietic cells and antigen-specific CD8 T cells prevents effector CD8 T cells from killing virus-infected cells (Fig. 4) (Mueller et al. 2010). Thus, this model indicates that PD-1 blockade therapy acts at two levels: (1) T-cell activation by blocking PD-1/PD-1 ligand interaction between T cells and APCs and (2) target cell elimination by inhibiting the interaction between T cells and target cells (infected cells or tumors) (Fig. 4). Although this model is based on naïve CD8 T-cell activation during infection, the same mechanism could be used by exhausted CD8 T cells in chronically infected animals. Thus, these two distinct mechanisms of action with PD-1 blockade against chronic infection and cancer seem to lead to striking outcomes compared with other immunotherapies.

\section{Combination Therapy with PD-1 Blockade}

The broad efficacy of PD-1 blockade against many chronic infections and cancer suggests that PD-1 is a major regulator of CD8 T-cell exhaustion. This implies that other immunotherapeutic strategies that interrupt different signaling pathways may not efficiently revive exhausted CD8 T cells owing to the predominant inhibitory signals from PD-1. Indeed, PD-1 blockade therapy often shows the highest efficacy to enhance CD8 T-cell responses and regulate infections and tumor growth compared with other immunotherapies. Thus, other immunotherapies that have not shown significant improvement in 


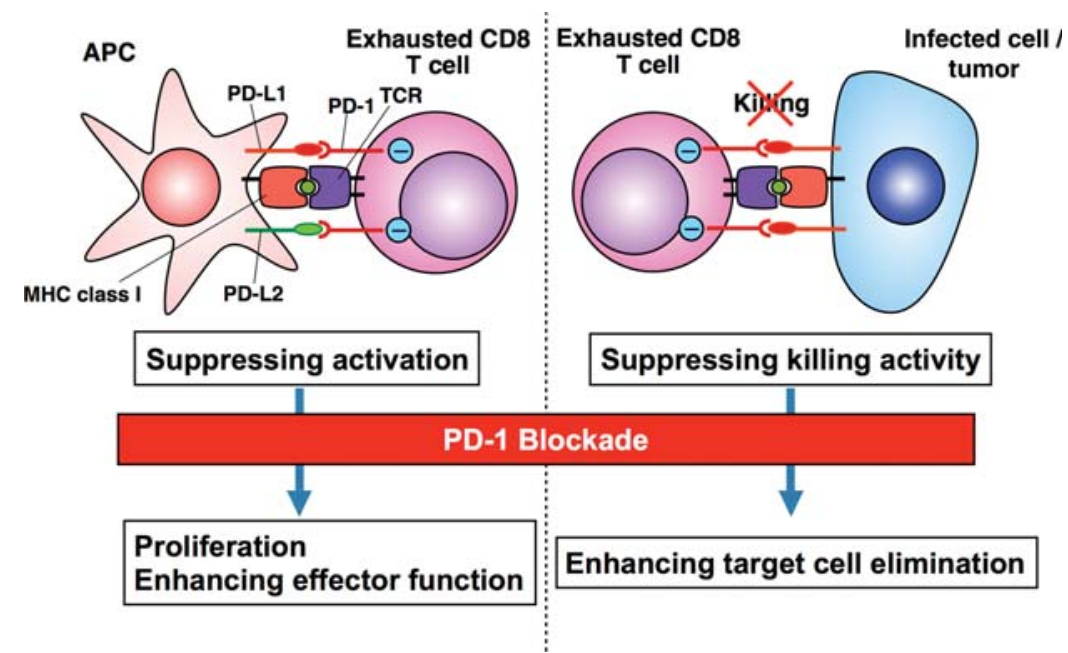

Figure 4. Potential mechanisms of PD-1-directed immunotherapy. PD-1/PD-1 ligand interaction between APCs and antigen-specific CD8 T cells inhibits expansion of exhausted CD8 T cells as well as effector T-cell differentiation (left). PD-1/PD-L1 interaction between target cells (infected nonhematopoietic cells or tumors) and antigen-specific CD8 T cells prevents the CD8 T cells from clearing the target cells (right). PD-1 blockade therapy acts at two levels: (1) T-cell activation by blocking PD-1/PD-1 ligand interaction between T cells and APCs (left) and (2) target cell elimination by inhibiting the interaction between T cells and target cells (infected cells or tumors) (right).

cytotoxic T lymphocyte (CTL) function may synergistically enhance efficacy of PD-1 blockade therapy. Here, we summarize potential combination therapies with PD-1 blockade for chronic infections and cancer.

Therapeutic Vaccination. Therapeutic vaccination has the potential to boost antipathogen or antitumor immune responses. The rationale behind therapeutic vaccination is that by enhancing preexisting immunity against chronic pathogens or tumors via delivering antigen to proper APCs such as DCs, antigen can then be efficiently presented to $\mathrm{T}$ cells along with costimulatory molecules (Fig. 5). However, these approaches often show only partial efficacy owing to T-cell exhaustion (Wherry et al. 2005). Proliferation capacity of exhausted CD8 T cells is limited even after stimulation with DCs. Because PD-1 expression significantly contributes to T-cell exhaustion, it was postulated that blockade of the PD-1 pathway could overcome the limitation of therapeutic vaccination. Indeed, blocking PD-1/PD-L1 interaction in combination with therapeutic vaccination synergistically improved antiviral CD8 T-cell immunity and enhanced viral control in mice chronically infected with LCMV (Ha et al. 2008).

Blockade of Other Inhibitory Receptors. Although PD-1 has a major role in T-cell exhaustion during chronic infection, exhausted CD8 T cells express several other inhibitory receptors involved in functional impairment of CD8 T cells (Fig. 5) (Wherry et al. 2007; Blackburn et al. 2009). Coexpression of multiple inhibitory receptors is linked to severe T-cell exhaustion and impaired viral control (Blackburn et al. 2009). Because dysfunction of $\mathrm{T}$ cells by these distinct inhibitory receptors is mediated by their unique ligands expressed on target cells and/or APCs, combination immunotherapy with these inhibitory receptors can synergistically enhance T-cell immunity against chronic infections or tumors.

LAG-3 is a cell-surface molecule expressed on multiple immune cells including activated T cells, regulatory $\mathrm{T}$ cells (Tregs), and exhausted CD8 T cells (Goldberg and Drake 2011). Although the exact function of LAG-3 in the immune system is yet to be fully understood, it seems that exhausted CD8 T cells use LAG-3 to suppress T-cell responses (Blackburn et al. 2009). Anti-LAG-3 blocking antibody alone has minimal effects on improvement of virus-specific CD8 T-cell responses during chronic LCMV infection but simultaneous blockade of PD-1 and LAG-3 pathways significantly enhances T-cell immunity and viral control (Blackburn et al. 2009). An independent study has shown that combined LAG-3/PD-1 blockade treatment rapidly clears established blood-stage malaria infection in mice by improving CD4 T-cell responses (Butler et al. 2012). These data provide a proof of principle that efficacy of PD-1 blockade can be increased when signaling of other inhibitory receptors is simultaneously prevented.

Tim-3 is another inhibitory molecule that has potential to improve T-cell immunity during chronic infections (Zhu et al. 2011). Tim-3 was originally identified on $\mathrm{T}$ helper 1 (Th1) (Monney et al. 2002) but not on Th2, and it is now apparent that exhausted CD8 T cells also express Tim-3 (Jin et al. 2010). Its ligand, galectin-9, is broadly expressed in many tissues, and interaction of Tim-3 with galectin-9 negatively regulates T-cell responses (Zhu et al. 2011). Like anti-LAG-3 antibody treatment, monotherapy with Tim-3Ig to block the Tim-3 pathway in vivo has minimal effects on T-cell immunity against chronic LCMV infection (Jin et al. 2010). Importantly, combined blockade of Tim-3 and PD-1 pathways synergistically restores the number and function of exhausted CD8 T cells and enhances viral control (Jin et al. 2010). Tim-3/PD-1 

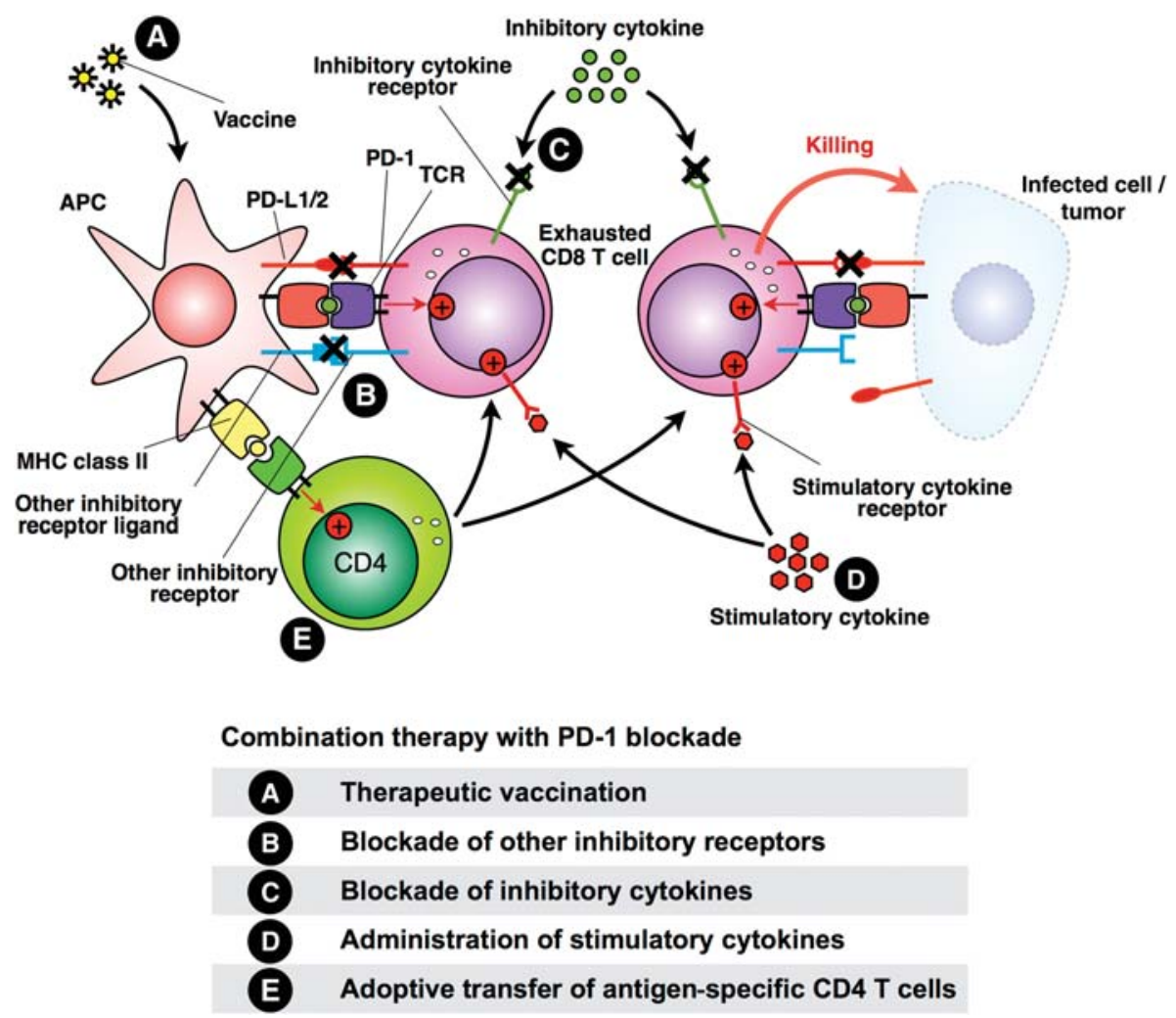

Figure 5. Potential combination therapies with PD-1 blockade. $(A)$ Therapeutic vaccine, $(B)$ blocking other inhibitory receptors such as Tim-3, LAG-3, and CTLA-4, $(C)$ blocking inhibitory cytokines such as IL-10, $(D)$ activating exhausted CD8 T cells with stimulatory cytokines (IL-2 etc.), and $(E)$ adoptive transfer of antigen-specific CD4 T cells.

combination therapy also has beneficial effects on controlling tumor growth in a mouse model (Sakuishi et al. 2010). Several clinical studies suggested that this therapy may be applicable in human with chronic infections or cancer (Fourcade et al. 2010; Afanasiev et al. 2013). Tim-3 is expressed on a part of tumor-specific CD8 T cells in human patients with advanced melanoma and Tim- $3^{+}$ PD- $1^{+}$tumor-specific CD8 T cells are associated with severe exhaustion (Fourcade et al. 2010). The same study has shown that Tim-3 blockade together with PD-1 blockade in vitro improves the function of human tumor-specific CD8 T cells (Fourcade et al. 2010). Thus, Tim-3 can be targeted to control chronic infections as well as tumor growth combined with inhibition of the PD-1 pathway.

CTLA-4 is another candidate molecule for combination therapy with PD-1 blockade (Teft et al. 2006; Hamid et al. 2013; Wolchok et al. 2013). Anti-CTLA-4 antibody treatment has been approved by the Food and Drug administration for patients with late-stage melanoma (Lipson and Drake 2011). CTLA-4 is up-regulated on activated and exhausted T cells and is thought to inhibit T-cell responses (Wherry et al. 2007). CTLA-4 is also found on Tregs and plays an essential role in inhibitory functions of Tregs (Wing et al. 2008). Its ligands, B7-1 (CD80) and B7-2 (CD86), are mainly expressed on DCs, B cells, macrophages, and activated $\mathrm{T}$ cells. These ligands also bind to a costimulatory molecule CD28 that is important for Tcell activation, but CTLA-4 can effectively inhibit T-cell responses because it serves a higher affinity for B7 molecules than does CD28 (Greenwald et al. 2005). Modulating this pathway with anti-CTLA-4 blocking antibody improves overall survival in patients with advanced melanoma (Lipson and Drake 2011). Although the underlying mechanism is thought to be that the blockade acts on inhibitory effects of CTLA-4 on both antitumor T cells and Tregs, a recent mouse study suggested that antiCTLA-4 antibody treatment worked by depleting tumorinfiltrating Tregs (Simpson et al. 2013). Regardless of the mechanisms of action, combination therapy of this anti-CTLA-4 antibody treatment and blockade of the PD-1 pathway in mice promotes more pronounced rejection of melanoma than either alone (Curran et al. 2010). Moreover, the combination therapy in a small clinical trial also showed more rapid and strong tumor responses in patients with advance melanoma compared with previous monotherapy data (Wolchok et al. 2013). Although further confirmation with large clinical trials is required, these data hold considerable promise in treating cancer patients.

Modulating Cytokine Signals. In addition to membrane-bound inhibitory receptors, soluble inhibitory molecules regulate T-cell exhaustion (Fig. 5). IL-10 is an immunosuppressive cytokine and is primarily produced by mononuclear cells including macrophages, Th2, CD8 T cells, and Tregs (Saraiva and O'Garra 2010). Specifi- 
cally, antigen-specific CD8 T cells from chronically infected humans and mice can express significant levels of IL-10 (Elrefaei et al. 2006, 2007; Jin et al. 2010). It has been shown that IL-10 has an important role in CD8 Tcell exhaustion and that blocking the IL-10 signal using anti-IL-10 receptor antibody enhances viral control and T-cell function during chronic LCMV infection (Brooks et al. 2006). Additionally, concurrent treatment with PD1 blockade and anti-IL-10 receptor antibody further improves therapeutic efficacy in chronically LCMV-infected mice (Brooks et al. 2008).

In contrast to immunoinhibitory cytokines, we found that the immunostimulatory cytokine IL-2 can promote T-cell responses during chronic infections (Fig. 5) (Blattman et al. 2003). IL-2 is a cytokine that has multiple effects on a variety of immune cells. IL-2 can enhance protective $\mathrm{T}$-cell immunity by supporting proliferation and survival of effector $\mathrm{T}$ cells but it can also negatively regulate immune responses by increasing the number of Tregs that constitutively express IL-2 receptor $\alpha$ (Waldmann 2006). Because of this contradictory activity of IL2 , some studies showed beneficial results of providing exogenous IL-2 for control of chronic infections and tumor growth, whereas limited successes were observed in other studies (Waldmann 2006). However, we have previously found that IL-2 therapy during chronic LCMV infection results in notable immunostimulatory effects on exhausted CD8 T cells, leading to better viral control (Blattman et al. 2003). Importantly, combined IL-2 therapy and PD-1 blockade synergistically enhances virusspecific CD8 T-cell responses during chronic LCMV infection and strikingly reduces virus load compared with either treatment given alone (West et al. 2013). These data indicate that combining immunostimulatory cytokine treatment with blockade of the PD-1 inhibitory pathway has potential to control chronic infections and tumors (Fig. 5). In addition to IL-2, it will be interesting to examine whether PD-1 blockade synergizes with other cytokine therapy such as IL-7 and IL-21 for reinvigorating exhausted T cells.

Adoptive Immunotherapy. In addition to modulating cellular signaling pathways by antibodies or cytokines as described above, immunotherapies based on adoptive Tcell transfer have shown promising results in controlling cancer (Restifo et al. 2012). Specifically, recent clinical trials targeting CD19 expressing acute and chronic lymphoid leukemia showed that adoptive transfer of lentivirus-transduced autologous $\mathrm{T}$ cells that had chimeric antigen receptor with specificity for CD19 coupled with a T-cell signaling molecule successfully eliminated CD19 expressing tumors by directly lysing them (Porter et al. 2011; Grupp et al. 2013). Similarly, genetically engineered CD8 T cells that express tumor-specific TCRs are also attractive to cure patients with cancer (Restifo et al. 2012). Can PD-1 blockade therapy improve the efficacy of these adoptive immunotherapies? Because $\mathrm{T}$ cells transferred into patients will significantly up-regulate PD-1 after encountering antigen, PD-1 blockade could enhance the effect of therapies.
Interestingly, we have recently shown that adoptive transfer of LCMV-specific CD4 T cells into mice chronically infected with LCMV restores proliferation and cytokine production by exhausted CD8 T cells and reduces viral load (Fig. 5) (Aubert et al. 2011). How antigenspecific CD4 T-cell transfer rescues exhausted CD8 T cells remains an important unanswered question. One possible mechanism is that cytokines produced by activated CD4 T cells act directly on exhausted CD8 T cells. Based on the previously described experiments demonstrating that exogenous IL-2 administration enhances CD8 T-cell responses during chronic infection (Blattman et al. 2003), a potential hypothesis may be that IL-2 produced by antigen-specific CD4 $\mathrm{T}$ cells after adoptive transfer may rescue the exhausted CD8 T cells. Also, several studies have shown that another cytokine IL-21 has a critical role in maintaining effector function of CD8 T cells during chronic infections (Elsaesser et al. 2009; Frohlich et al. 2009; Yi et al. 2009). Thus, IL-21 produced by transferred CD4 T cells could be an essential factor for this therapy. In the same study, PD-1 blockade therapy was combined with antigen-specific CD4 T-cell transfer into chronically infected mice (Aubert et al. 2011). The efficacy of CD4 T-cell transfer was further augmented by PD-1 blockade, and better viral control and improved rescue of exhausted CD8 T cells were observed (Aubert et al. 2011). Thus, the study supports developing adoptive CD4 T-cell therapy combined with PD-1 blockade to reinvigorate preexisting exhausted CD8 T cells for treating patients with chronic diseases.

\section{CONCLUSIONS}

PD-1 is a major regulator of T-cell exhaustion, and its blockade therapy can revive exhausted T cells. Combination therapy with PD-1 blockade can synergistically improve the function of exhausted CD8 $\mathrm{T}$ cells. Thus, immunotherapy directed at PD-1 has significant potential to control many chronic infections and cancer. Although it is clear that PD-1 plays an essential role in T-cell exhaustion, much less is known about molecular mechanisms of PD-1-mediated T-cell exhaustion. Toward better understanding of exhausted T cells and developing more effective immunotherapy targeting PD-1, it is important to uncover how intracellular signals of PD-1 regulate T-cell exhaustion and how blocking the PD-1 pathway rejuvenates exhausted $\mathrm{T}$ cells.

\section{ACKNOWLEDGMENTS}

This work was supported by the National Institutes of Health grants AI030048 and AI088575 to R.A.

\section{REFERENCES}

Afanasiev OK, Yelistratova L, Miller N, Nagase K, Paulson K, Iyer JG, Ibrani D, Koelle DM, Nghiem P. 2013. Merkel polyomavirus-specific $\mathrm{T}$ cells fluctuate with merkel cell carcinoma burden and express therapeutically targetable 
PD-1 and Tim-3 exhaustion markers. Clin Cancer Res 19: 5351-5360.

Angelosanto JM, Blackburn SD, Crawford A, Wherry EJ. 2012. Progressive loss of memory T cell potential and commitment to exhaustion during chronic viral infection. $J$ Virol 86: 8161-8170.

Aubert RD, Kamphorst AO, Sarkar S, Vezys V, Ha SJ, Barber DL, Ye L, Sharpe AH, Freeman GJ, Ahmed R. 2011. Antigenspecific CD4 T-cell help rescues exhausted CD8 T cells during chronic viral infection. Proc Natl Acad Sci 108: $21182-$ 21187.

Barber DL, Wherry EJ, Masopust D, Zhu B, Allison JP, Sharpe AH, Freeman GJ, Ahmed R. 2006. Restoring function in exhausted CD8 T cells during chronic viral infection. Nature 439: $682-687$.

Blackburn SD, Shin H, Haining WN, Zou T, Workman CJ, Polley A, Betts MR, Freeman GJ, Vignali DA, Wherry EJ. 2009. Coregulation of CD8 $+\mathrm{T}$ cell exhaustion by multiple inhibitory receptors during chronic viral infection. Nat Immunol 10: 29-37.

Blattman JN, Grayson JM, Wherry EJ, Kaech SM, Smith KA, Ahmed R. 2003. Therapeutic use of IL-2 to enhance antiviral T-cell responses in vivo. Nat Med 9: 540-547.

Blattman JN, Wherry EJ, Ha SJ, van der Most RG, Ahmed R. 2009. Impact of epitope escape on PD-1 expression and CD8 T-cell exhaustion during chronic infection. J Virol 83: 43864394.

Brahmer JR, Tykodi SS, Chow LQ, Hwu WJ, Topalian SL, Hwu P, Drake CG, Camacho LH, Kauh J, Odunsi K, et al. 2012. Safety and activity of anti-PD-L1 antibody in patients with advanced cancer. $N$ Engl J Med 366: 2455-2465.

Brooks DG, Trifilo MJ, Edelmann KH, Teyton L, McGavern DB, Oldstone MB. 2006. Interleukin-10 determines viral clearance or persistence in vivo. Nat Med 12: 1301-1309.

Brooks DG, Ha SJ, Elsaesser H, Sharpe AH, Freeman GJ, Oldstone MB. 2008. IL-10 and PD-L1 operate through distinct pathways to suppress T-cell activity during persistent viral infection. Proc Natl Acad Sci 105: 20428-20433.

Butler NS, Moebius J, Pewe LL, Traore B, Doumbo OK, Tygrett LT, Waldschmidt TJ, Crompton PD, Harty JT. 2012. Therapeutic blockade of PD-L1 and LAG-3 rapidly clears established blood-stage Plasmodium infection. Nat Immunol 13: $188-195$.

Curran MA, Montalvo W, Yagita H, Allison JP. 2010. PD-1 and CTLA-4 combination blockade expands infiltrating T cells and reduces regulatory $\mathrm{T}$ and myeloid cells within $\mathrm{B} 16$ melanoma tumors. Proc Natl Acad Sci 107: 4275-4280.

Day CL, Kaufmann DE, Kiepiela P, Brown JA, Moodley ES, Reddy S, Mackey EW, Miller JD, Leslie AJ, DePierres C, et al. 2006. PD-1 expression on HIV-specific T cells is associated with T-cell exhaustion and disease progression. Nature 443: $350-354$

Elrefaei M, Barugahare B, Ssali F, Mugyenyi P, Cao H. 2006. HIV-specific IL-10-positive CD8 + T cells are increased in advanced disease and are associated with decreased HIV-specific cytolysis. J Immunol 176: 1274-1280.

Elrefaei M, Ventura FL, Baker CA, Clark R, Bangsberg DR, Cao H. 2007. HIV-specific IL-10-positive CD8+ T cells suppress cytolysis and IL-2 production by CD8 $+\mathrm{T}$ cells. J Immunol 178: $3265-3271$.

Elsaesser H, Sauer K, Brooks DG. 2009. IL-21 is required to control chronic viral infection. Science 324: 1569-1572.

Fourcade J, Sun Z, Benallaoua M, Guillaume P, Luescher IF, Sander C, Kirkwood JM, Kuchroo V, Zarour HM. 2010. Upregulation of Tim-3 and PD-1 expression is associated with tumor antigen-specific CD8 $+\mathrm{T}$ cell dysfunction in melanoma patients. J Exp Med 207: 2175-2186.

Francisco LM, Sage PT, Sharpe AH. 2010. The PD-1 pathway in tolerance and autoimmunity. Immunol Rev 236: 219-242.

Frohlich A, Kisielow J, Schmitz I, Freigang S, Shamshiev AT, Weber J, Marsland BJ, Oxenius A, Kopf M. 2009. IL-21R on $\mathrm{T}$ cells is critical for sustained functionality and control of chronic viral infection. Science 324: 1576-1580.
Fuller MJ, Callendret B, Zhu B, Freeman GJ, Hasselschwert DL, Satterfield W, Sharpe AH, Dustin LB, Rice CM, Grakoui A, et al. 2013. Immunotherapy of chronic hepatitis $C$ virus infection with antibodies against programmed cell death-1 (PD1). Proc Natl Acad Sci 110: 15001-15006.

Goldberg MV, Drake CG. 2011. LAG-3 in cancer immunotherapy. Curr Top Microbiol Immunol 344: 269-278.

Greenwald RJ, Freeman GJ, Sharpe AH. 2005. The B7 family revisited. Аnпu Rev Immunol 23: 515-548.

Grupp SA, Kalos M, Barrett D, Aplenc R, Porter DL, Rheingold SR, Teachey DT, Chew A, Hauck B, Wright JF, et al. 2013. Chimeric antigen receptor-modified $\mathrm{T}$ cells for acute lymphoid leukemia. N Engl J Med 368: 1509-1518.

Ha SJ, Mueller SN, Wherry EJ, Barber DL, Aubert RD, Sharpe AH, Freeman GJ, Ahmed R. 2008. Enhancing therapeutic vaccination by blocking $\mathrm{PD}-1$-mediated inhibitory signals during chronic infection. J Exp Med 205: 543-555.

Hamid O, Robert C, Daud A, Hodi FS, Hwu WJ, Kefford R, Wolchok JD, Hersey P, Joseph RW, Weber JS, et al. 2013. Safety and tumor responses with lambrolizumab (anti-PD-1) in melanoma. $N$ Engl J Med 369: 134-144.

Jin HT, Anderson AC, Tan WG, West EE, Ha SJ, Araki K, Freeman GJ, Kuchroo VK, Ahmed R. 2010. Cooperation of Tim-3 and PD-1 in CD8 T-cell exhaustion during chronic viral infection. Proc Natl Acad Sci 107: 1473314738 .

Kaech SM, Wherry EJ. 2007. Heterogeneity and cell-fate decisions in effector and memory CD8 $+\mathrm{T}$ cell differentiation during viral infection. Immunity 27: 393-405.

Kao C, Oestreich KJ, Paley MA, Crawford A, Angelosanto JM, Ali MA, Intlekofer AM, Boss JM, Reiner SL, Weinmann AS, et al. 2011. Transcription factor T-bet represses expression of the inhibitory receptor PD-1 and sustains virus-specific $\mathrm{CD} 8+\mathrm{T}$ cell responses during chronic infection. Nat Immunol 12: 663-671.

Keir ME, Butte MJ, Freeman GJ, Sharpe AH. 2008. PD-1 and its ligands in tolerance and immunity. Аnпu Rev Immunol 26: 677-704.

Lipson EJ, Drake CG. 2011. Ipilimumab: An anti-CTLA-4 antibody for metastatic melanoma. Clin Cancer Res 17: 69586962.

Monney L, Sabatos CA, Gaglia JL, Ryu A, Waldner H, Chernova T, Manning S, Greenfield EA, Coyle AJ, Sobel RA, et al. 2002. Th1-specific cell surface protein Tim-3 regulates macrophage activation and severity of an autoimmune disease. Nature 415: 536-541.

Mueller SN, Vanguri VK, Ha SJ, West EE, Keir ME, Glickman JN, Sharpe AH, Ahmed R. 2010. PD-L1 has distinct functions in hematopoietic and nonhematopoietic cells in regulating $\mathrm{T}$ cell responses during chronic infection in mice. J Clin Invest 120: $2508-2515$.

Oestreich KJ, Yoon H, Ahmed R, Boss JM. 2008. NFATc1 regulates PD-1 expression upon T cell activation. J Immunol 181: $4832-4839$.

Petrovas C, Casazza JP, Brenchley JM, Price DA, Gostick E, Adams WC, Precopio ML, Schacker T, Roederer M, Douek DC, et al. 2006. PD-1 is a regulator of virus-specific CD8+ $\mathrm{T}$ cell survival in HIV infection. $J$ Exp Med 203: $2281-$ 2292.

Porter DL, Levine BL, Kalos M, Bagg A, June CH. 2011. Chimeric antigen receptor-modified $\mathrm{T}$ cells in chronic lymphoid leukemia. $N$ Engl J Med 365: 725-733.

Radziewicz H, Ibegbu CC, Fernandez ML, Workowski KA, Obideen K, Wehbi M, Hanson HL, Steinberg JP, Masopust D, Wherry EJ, et al. 2007. Liver-infiltrating lymphocytes in chronic human hepatitis $\mathrm{C}$ virus infection display an exhausted phenotype with high levels of PD-1 and low levels of CD127 expression. J Virol 81: 2545-2553.

Restifo NP, Dudley ME, Rosenberg SA. 2012. Adoptive immunotherapy for cancer: Harnessing the T cell response. Nat Rev Immunol 12: 269-281.

Ribas A. 2012. Tumor immunotherapy directed at PD-1. NEngl J Med 366: 2517-2519. 
Rudd CE, Taylor A, Schneider H. 2009. CD28 and CTLA-4 coreceptor expression and signal transduction. Immunol Rev 229: $12-26$

Sakuishi K, Apetoh L, Sullivan JM, Blazar BR, Kuchroo VK, Anderson AC. 2010. Targeting Tim-3 and PD-1 pathways to reverse $\mathrm{T}$ cell exhaustion and restore anti-tumor immunity. $J$ Exp Med 207: 2187-2194

Saraiva M, O'Garra A. 2010. The regulation of IL-10 production by immune cells. Nat Rev Immunol 10: 170-181.

Simpson TR, Li F, Montalvo-Ortiz W, Sepulveda MA, Bergerhoff K, Arce F, Roddie C, Henry JY, Yagita H, Wolchok JD, et al. 2013. Fc-dependent depletion of tumor-infiltrating regulatory T cells co-defines the efficacy of anti-CTLA-4 therapy against melanoma. $J$ Exp Med 210: 1695-1710.

Teft WA, Kirchhof MG, Madrenas J. 2006. A molecular perspective of CTLA-4 function. Annu Rev Immunol 24: 65-97.

Topalian SL, Hodi FS, Brahmer JR, Gettinger SN, Smith DC, McDermott DF, Powderly JD, Carvajal RD, Sosman JA, Atkins MB, et al. 2012. Safety, activity, and immune correlates of anti-PD-1 antibody in cancer. $N$ Engl J Med 366: $2443-$ 2454.

Trautmann L, Janbazian L, Chomont N, Said EA, Gimmig S, Bessette B, Boulassel MR, Delwart E, Sepulveda H, Balderas $\mathrm{RS}$, et al. 2006. Upregulation of PD-1 expression on HIVspecific CD8 + T cells leads to reversible immune dysfunction. Nat Med 12: 1198-1202.

Urbani S, Amadei B, Tola D, Massari M, Schivazappa S, Missale G, Ferrari C. 2006. PD-1 expression in acute hepatitis C virus (HCV) infection is associated with $\mathrm{HCV}$-specific $\mathrm{CD} 8$ exhaustion. J Virol 80: 11398-11403.

Velu V, Titanji K, Zhu B, Husain S, Pladevega A, Lai L, Vanderford TH, Chennareddi L, Silvestri G, Freeman GJ, et al. 2009. Enhancing SIV-specific immunity in vivo by PD-1 blockade. Nature 458: 206-210.

Waldmann TA. 2006. The biology of interleukin-2 and interleukin-15: Implications for cancer therapy and vaccine design. Nat Rev Immunol 6: 595-601.

West EE, Jin HT, Rasheed AU, Penaloza-Macmaster P, Ha SJ, Tan WG, Youngblood B, Freeman GJ, Smith KA, Ahmed R. 2013. PD-L1 blockade synergizes with IL-2 therapy in reinvigorating exhausted T cells. J Clin Invest 123: 2604 2615.

Wherry EJ, Blattman JN, Ahmed R. 2005. Low CD8 T-cell proliferative potential and high viral load limit the effectiveness of therapeutic vaccination. J Virol 79: 8960-8968.

Wherry EJ, Ha SJ, Kaech SM, Haining WN, Sarkar S, Kalia V, Subramaniam S, Blattman JN, Barber DL, Ahmed R. 2007. Molecular signature of CD8 + T cell exhaustion during chronic viral infection. Immunity 27: 670-684.

Wing K, Onishi Y, Prieto-Martin P, Yamaguchi T, Miyara M, Fehervari Z, Nomura T, Sakaguchi S. 2008. CTLA-4 control over Foxp3 + regulatory T cell function. Science 322: $271-$ 275.

Wolchok JD, Kluger H, Callahan MK, Postow MA, Rizvi NA, Lesokhin AM, Segal NH, Ariyan CE, Gordon RA, Reed K, et al. 2013. Nivolumab plus ipilimumab in advanced melanoma. N Engl J Med 369: 122-133.

Xiao G, Deng A, Liu H, Ge G, Liu X. 2012. Activator protein 1 suppresses antitumor T-cell function via the induction of programmed death 1. Proc Natl Acad Sci 109: 15419-15424.

Yi JS, Du M, Zajac AJ. 2009. A vital role for interleukin-21 in the control of a chronic viral infection. Science 324: 1572 1576.

Youngblood B, Oestreich KJ, Ha SJ, Duraiswamy J, Akondy RS, West EE, Wei Z, Lu P, Austin JW, Riley JL, et al. 2011. Chronic virus infection enforces demethylation of the locus that encodes PD-1 in antigen-specific CD8 $(+)$ T cells. Immunity 35: 400-412.

Youngblood B, Noto A, Porichis F, Akondy RS, Ndhlovu ZM, Austin JW, Bordi R, Procopio FA, Miura T, Allen TM, et al. 2013. Cutting edge: Prolonged exposure to HIV reinforces a poised epigenetic program for PD-1 expression in virus-specific CD8 T cells. J Immunol 191: 540-544.

Zajac AJ, Blattman JN, Murali-Krishna K, Sourdive DJ, Suresh M, Altman JD, Ahmed R. 1998. Viral immune evasion due to persistence of activated T cells without effector function. $J$ Exp Med 188: 2205-2213.

Zhu C, Anderson AC, Kuchroo VK. 2011. TIM-3 and its regulatory role in immune responses. Curr Top Microbiol Immunol 350: $1-15$. 


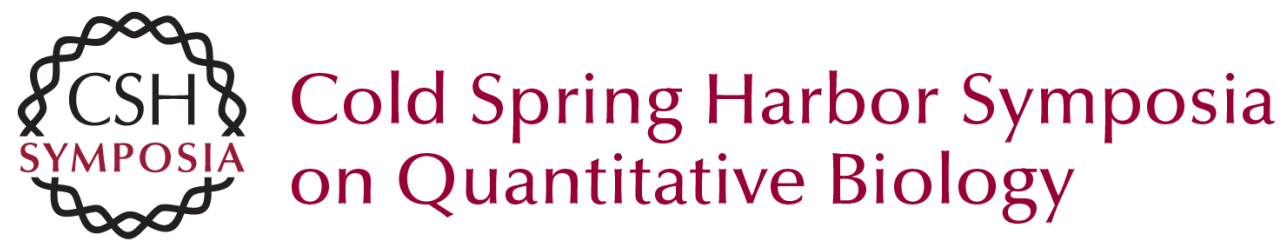

\section{Programmed Cell Death 1-Directed Immunotherapy for Enhancing T-Cell Function}

Koichi Araki, Ben Youngblood and Rafi Ahmed

Cold Spring Harb Symp Quant Biol 2013 78: 239-247 originally published online January 10, 2014

Access the most recent version at doi:10.1101/sqb.78.019869

References This article cites 59 articles, 27 of which can be accessed free at: http://symposium.cshlp.org/content/78/239.full.html\#ref-list-1

\section{License}

Email Alerting Receive free email alerts when new articles cite this article - sign up in Service the box at the top right corner of the article or click here. 